\title{
High Efficiency Hybrid Silicon Nanopillar-Polymer Solar Cells
}

\author{
Pushpa Raj Pudasainia, ${ }^{,}$, Francisco Ruiz-Zepeda ${ }^{a}$, Manisha Sharma ${ }^{b}$, David Elam ${ }^{a}$, Arturo \\ Ponce ${ }^{\mathrm{a}}$, and Arturo A Ayon ${ }^{\mathrm{a}}$ \\ aDepartment of Physics and Astronomy, University of Texas at San Antonio, One UTSA Circle, \\ San Antonio, TX, 78249, USA \\ bDepartment of Chemistry, University of Texas at San Antonio, One UTSA Circle, San Antonio, \\ TX, 78249, USA
}

\section{Abstract}

Recently, inorganic/organic hybrid solar cells have been considered as a viable alternative for lowcost photovoltaic devices because the Schottky junction between inorganic and organic materials can be formed employing low temperature processing methods. We present an efficient hybrid solar cell based on highly ordered silicon nanopillars (SiNPs) and poly (3,4-ethylenedioxythiophene):polystyrenesulfonate (PEDOT:PSS). The proposed device is formed by spin coating the organic polymer PEDOT:PSS on a SiNP array fabricated using metal assisted electroless chemical etching process. The characteristics of the hybrid solar cells are investigated as a function of SiNP height. A maximum power conversion efficiency (PCE) of $9.65 \%$ has been achieved for an optimized SiNP array hybrid solar cell with nanopillar height of $400 \mathrm{~nm}$, despite the absence of a back surface field enhancement. The effect of an ultrathin atomic layer deposition (ALD), grown aluminum oxide $\left(\mathrm{Al}_{2} \mathrm{O}_{3}\right)$, as a passivation layer (recombination barrier) has also been studied for the enhanced electrical performance of the device. With the inclusion of the ultrathin ALD deposited $\mathrm{Al}_{2} \mathrm{O}_{3}$ between the SiNP array textured surface and the PEDOT:PSS layer, the $P C E$ of the fabricated device was observed to increase to $10.56 \%$, which is $\sim 10 \%$ greater than the corresponding device without the $\mathrm{Al}_{2} \mathrm{O}_{3}$ layer. The device described herein is considered to be promising toward the realization of a low-cost, high-efficiency inorganic/organic hybrid solar cell.

\section{Keywords}

Solar cell; light trapping; heterojunction; conductive polymer; silicon nanopillars; radial junction

*Corresponding Author: Phone: 210-458-6562, pbz620@my.utsa.edu.

Supporting Information Available

Figures S1 and S2 and Table T1, in details: Figure S1. Cross-sectional SEM image of PEDOT:PSS coated SiNP array, Figure S2. EDX spectra obtained at the interface of the $\mathrm{Al}_{2} \mathrm{O}_{3}$ film and $\mathrm{Si}$ substrate and Table T1. photovoltaic performance parameters of SiNP/ PEDOT:PSS hybrid solar cells with and without $\mathrm{Al}_{2} \mathrm{O}_{3}$ passivation layer after 72 hours exposure in air. This materials is available free of charge via the internet at http://pubs.acs.org. 


\section{Introduction}

Crystalline silicon (c-Si) has enjoyed years of success in the photovoltaic industry due to its relatively high power conversion efficiencies $(P C E) .{ }^{1-4}$ In addition, it exhibits other advantages such as high abundance, nontoxicity, and well-established processing technologies. Nonetheless, photovoltaic devices based on c-Si are relatively expensive compared to other photovoltaic technologies, mainly due to the relatively complex high temperature fabrication steps involved, as well as the required thickness of the c-Si wafer to absorb most of the solar spectrum due to its indirect band gap. On the other hand, organic photovoltaic (OPV) devices based on conjugated polymers, which can be fabricated by relatively simple, low temperature techniques utilizing inexpensive materials, have the potential for demonstrating low cost photovoltaic devices. ${ }^{5-10}$ However, as of today, stateof-the-art organic solar cells exhibit relatively low PCE compared to their c-Si counterparts. One of the greatest challenges of OPV is the relative paucity of electron accepting materials which may be paired with hole conducting polymers to induce exciton dissociation at the interface. An interesting approach to this problem is to use semiconducting nanostructures as an electron accepting phase to form organic/inorganic hybrid solar cells. Therefore, hybrid solar cells based on inorganic semiconductors and organic conjugated polymers combine both of their advantages and provide a possible alternative route to enable low cost photovoltaic devices. ${ }^{11-18}$ A commonly used organic material for hybrid PV devices is the conjugated polymer, poly(3,4-ethylene dioxythiophene):poly-(styrenesulfonate) (PEDOT:PSS), which is transparent and conductive $(<1000 \mathrm{~S} / \mathrm{cm})$. Most of the incoming light is absorbed in the Si layer in Si/organic hybrid solar cells, thus, the $P C E$ of the device, in principle, may be comparable to conventional Si p-n junction solar cells. However, to the best of our knowledge, the power conversion efficiencies of Si/organic polymer hybrid solar cells are relatively low ( 10\%), compared to conventional c-Si solar cells. ${ }^{13,14,19-22}$ Some of the challenges, such as excessive carrier recombination, decay of excitons within a diffusion length $<10 \mathrm{~nm}$, and interface carrier transport inside the polymer, cause serious limitations to the efficiency of the aforementioned Si/organic hybrid solar cells. ${ }^{16,23-26} \mathrm{In}$ order to address some of these issues, different groups have incorporated Si nanostructures like silicon nanowires (SiNWs), silicon nanocones ( $\mathrm{SiNCs}$ ), silicon nanopillars (SiNPs), etc. in the active polymer layer of a device. ${ }^{19,21,27}$ Additionally, the vertically aligned SiNWs have been reported to exhibit excellent light absorption characteristics both theoretically and experimentally. ${ }^{3,28-32}$ However, there is still a challenge to fabricate a densely packed SiNW array with nanowire spacing close to the exciton diffusion length and synthesizing a conductive polymer having low exciton binding energy, which can fill the nanowire to form a core-shell structure. The commercially available PEDOT:PSS solution does not wet easily the highly hydrophobic SiNW array textured surface and the spacing between the nanowires is normally too small to be filled with the conductive polymer to form a core-shell heterojunction. Therefore, other organic compounds are frequently added to ensure a complete coverage on the highly dense vertical SiNW array. Furthermore, the performance of a SiNW/organic polymer hybrid solar cell depends on the surface/interface preparation. Carrier recombination at the surface/interface of the SiNWs due to their large surface to volume ratio is a major impediment for the efficient hybrid solar cell devices. To this end, the conductivity and wettability of PEDOT:PSS, the spin coating parameters (spin casting 
speed and time) to control the thickness of the PEDOT:PSS layer on the textured Si surface, and the annealing temperature after the spin coating process could all influence the interface properties of a hybrid solar cell. A thin dielectric interface passivation layer between the $\mathrm{Si}$ and PEDOT:PSS layer could also have a significant effect on the PV performance of the proposed hybrid devices. Zhang et al. ${ }^{33}$ have reported that compared to a hydrogen terminated silicon (-H-Si) surface, the short circuit current density $\left(J_{S C}\right)$ of a planar $\mathrm{Si} /$ Poly(3-hexylthiophene) (P3HT) hybrid cell with an oxygen terminated silicon (-SiOx-Si) surface exhibits a 200-fold enhancement. This has been attributed to the formation of a thin native oxide ( $\mathrm{SiOx}$ ) layer leading to the formation of a favorable internal electric field at the interface for an efficient carrier extraction. For the methyl terminated silicon $\left(-\mathrm{CH}_{3}-\mathrm{Si}\right)$ surface decorated with platinum $(\mathrm{Pt})$ nanodots, they reported a $P C E$ as high as $5.9 \%$. The effect of interfacial native oxide as a passivation layer (recombination barrier) on the electrical performance of a planar Si/PEDOT:PSS hybrid solar cell was studied by $\mathrm{He} e t$ $a l .{ }^{34}$ A maximum power conversion efficiency of $10.6 \%$ was reported with a $1.5 \mathrm{~nm}$ interfacial SiOx layer between the Si (111) surface and the PEDOT:PSS layer. However, a thin native oxide layer is important but cannot be too large, because a thick oxide layer could create an insulating barrier for electrical transport, thereby deteriorating the solar cell performance. It was observed that, PEDOT:PSS promotes for the oxidation of SiNP array textured surface thereby increasing the SiOx layer thickness over time. Therefore, the performance of a hybrid SiNP/PEDOT:PSS device deteriorates by aging. Moreover, Khatri et al. reported an enhanced electrical performance of a Si/PEDOT:PSS hybrid device with the incorporation of green-tea modified multiwall carbon nanotubes as an interface recombination barrier. ${ }^{26}$ The investigation of determining the best passivating layer (recombination barrier) on a Si/PEDOT:PSS hybrid solar and the corresponding optimization is still underway.

In this paper, we report an efficient hybrid solar cell composed of a vertically aligned silicon nanopillar array (SiNP) and a PEDOT:PSS organic polymer employing an ultrathin ALD deposited $\mathrm{Al}_{2} \mathrm{O}_{3}$ passivation (barrier) layer. The relatively large spacing between the nanopillars, compared to the randomly oriented SiNWs fabricated by metal assisted electroless chemical etching, permitted a conformal polymer coating for the formation of a radial p-n junction. $\mathrm{ALD} \mathrm{Al}_{2} \mathrm{O}_{3}$ was chosen as a passivation layer (recombination barrier) due to its unique chemical and field effect passivation characteristics, as well as the ability of ALD to deposit high quality, conformal films on high aspect ratio surfaces, with angstrom level control of the film thickness at low temperature. The influence of an interfacial $\mathrm{Al}_{2} \mathrm{O}_{3}$ layer on carrier collection efficiency is directly reflected on the measured photovoltaic performance of the device. The maximum short circuit current density $\left(J_{S C}\right)$ and $P C E$ values of $30.1 \mathrm{~mA} / \mathrm{cm}^{2}$ and $10.56 \%$, respectively, were obtained for an optimized SiNPs/ PEDOT:PSS solar cell with 6 cycles for the interfacial ALD $\mathrm{Al}_{2} \mathrm{O}_{3}$. For a thicker interfacial $\mathrm{Al}_{2} \mathrm{O}_{3}$ corresponding to an increased number of ALD cycles, the measured PCE of the device deteriorated due to a larger series resistance. 


\section{Experimental details}

\subsection{Silicon nanopillar array fabrication}

Highly ordered wafer scale SiNP arrays were fabricated by metal assisted electroless chemical etching in combination with nanosphere lithography. The detailed fabrication procedure can be found elsewhere. ${ }^{35-37}$ Summarily, a 1-2 $\mathrm{ml}$ of polystyrene (PS) nanoparticle suspension with nanoparticle size of $650 \mathrm{~nm}$ (Duke Scientific, Palo Alto, CA) diluted with methanol and Triton X-100, was spin coated on a previously cleaned n-type silicon (100) wafer to form a self assembled monolayer. The PS nanoparticle coated samples were exposed to an $\mathrm{O}_{2}$ plasma in a commercial barrel etcher to shrink the size of PS particles. Then a few nanometers of gold ( $\mathrm{Au}$ ) were deposited on the PS coated samples. A honeycomb-like Au pattern on Si was then formed by removing the PS nanoparticles using sonication. Finally, the samples were immersed in an etching solution comprised of HF (49\%), $\mathrm{H}_{2} \mathrm{O}_{2}$ and DI water in the volume ratio of 3:1:7 to form a periodic SiNP array textured surface. The height of the SiNPs can be controlled by varying the Si etching time. The underlying Au layer was subsequently removed by immersing the samples in a gold etchant solution (Sigma-Aldrich). The schematic fabrication process of periodic SiNPs array is shown in Figure 1.

\subsection{Atomic layer deposition of $\mathrm{Al}_{2} \mathrm{O}_{3}$}

The ALD of $\mathrm{Al}_{2} \mathrm{O}_{3}$ was carried out with a Cambridge Nanotech Savanah 200 system. The platen temperature was maintained at $110^{\circ} \mathrm{C}$ during the deposition process. The precursors, trimethylaluminium (TMA) and water $\left(\mathrm{H}_{2} \mathrm{O}\right)$ were kept at room temperature. Nitrogen $\left(\mathrm{N}_{2}\right)$ was used as a carrier and purging gas. ALD is a deposition process that employs cyclical self-limiting gas-surface reactions. This self-limiting reaction property is important for a conformal deposition in high aspect ratio structures due to the time required for the reactant gases to fully diffuse into the narrow channel. The average growth rate of this process estimated over 100 cycles on a blank $\mathrm{Si}(100)$ wafer with a native oxide as measured with ellipsometry was $1.1 \AA$ /cycle. The index of refraction of the as deposited film was measured to be 1.71 .

\subsection{Device fabrication}

Prior to device fabrication, the produced SiNP array textured samples went through a rigorous cleaning procedure. At first, any polystyrene residues were removed by immersing the sample in a toluene solution $\left(99.9 \%\right.$, Sigma-Aldrich) at $50^{\circ} \mathrm{C}$ for $30 \mathrm{~min}$. Secondly, the samples were cleaned by immersing them in a solution consisting of $\mathrm{H}_{2} \mathrm{O}_{2}(30 \%), \mathrm{NH}_{4} \mathrm{OH}$ (37\%), and DI water in the volume ratio of $1: 1: 5$ at $80^{\circ} \mathrm{C}$ for 30 min to remove any other organic residues. The samples were transferred to a DI water bath for $10 \mathrm{~min}$. Again, the samples were immersed in a solution comprised of $\mathrm{H}_{2} \mathrm{O}_{2}(30 \%), \mathrm{HCl}(37 \%)$, and DI water in the volume ratio of $1: 1: 5$ at $80^{\circ} \mathrm{C}$ for 30 min to remove any metallic contamination. The samples were then transferred to a DI water bath for $10 \mathrm{~min}$. Finally, the samples were cleaned in a diluted HF (2\%) solution for $60 \mathrm{~s}$ to remove the native oxide. Immediately, the samples were transferred to the ALD chamber for the few cycles of $\mathrm{Al}_{2} \mathrm{O}_{3}$ deposition. Different samples were prepared with various thicknesses of $\mathrm{Al}_{2} \mathrm{O}_{3}$. Subsequently, $10 \mathrm{~nm}$ of nickel and $400 \mathrm{~nm}$ of silver were deposited on the back side and the samples were annealed 
at $425^{\circ} \mathrm{C}$ for $30 \mathrm{~min}$ to form a rear contact. Highly conductive PEDOT:PSS (Sigma-Aldrich) mixed with dimethyl sulphoxide and Triton X-100 (surfactant) solution was spin cast at 300 $\mathrm{rpm}$ for $10 \mathrm{~s}$ and $2000 \mathrm{rpm}$ for $60 \mathrm{~s}$ to form a core-shell radial junction. The samples were then annealed on a hotplate at $140^{\circ} \mathrm{C}$ for $10 \mathrm{~min}$ to remove the solvent. Finally, an ITO coated glass with a resistivity of 8-12 $\Omega /$ (Sigma-Aldrich) was employed as a front contact to complete the cell. Each device had an active area of $1 \mathrm{~cm}^{2}$. Different solar cell samples were also fabricated by the same procedure without the interfacial $\mathrm{Al}_{2} \mathrm{O}_{3}$ layer between the $\mathrm{Si}$ (100) surface and the PEDOT:PSS layer. Figure 2(a) depicts the schematic illustration of the fabrication of a SiNPs/PEDOT:PSS solar cells. The chemical structure of the PEDOT:PSS transparent conductive polymer is shown in Figure 2(b).

\subsection{Characterization}

The morphology of the samples was collected by using high-resolution scanning electron microscopy (SEM) with a Field emission gun Hitachi S-5500. Transmission electron microscopy (TEM) was used to obtain high-resolution images at the $\mathrm{Al}_{2} \mathrm{O}_{3}$ and silicon interface in a JEOL 2010F TEM microscope operated at $200 \mathrm{kV}$. The cross-sectional TEM samples were prepared through a conventional mechanical polishing process including cutting, grinding, polishing, and a final ion milling thinning step. The optical reflectance spectra measurements were performed by using a $U V$-VIS-NIR (Varian cary-5000) spectrometer equipped with integrating sphere. The PV measurement was performed using a solar simulator (Newport Sol2A) under AM 1.5G illumination $\left(1000 \mathrm{~W} / \mathrm{m}^{2}\right)$ at standard testing conditions. Prior each sample measurement, the simulator intensity was calibrated with a reference cell from Newport (Irvine CA, USA) to ensure that the irradiation variation was within 3\%. The external quantum efficiency $(E Q E)$ system used a $300 \mathrm{~W}$ Xenon light source with a spot size of $1 \mathrm{~mm} \times 3 \mathrm{~mm}$ and calibrated with a silicon photodetector also from Newport.

\section{Results and discussion}

\subsection{Characterization of SiNP/Organic hybrid structure}

Figure 3(a) includes a large SEM micrograph of the vertically aligned SiNP array (top view) fabricated by metal assisted electroless chemical etching methods. The same Figure 3(a) includes an inset in the upper right corner with higher magnification SEM micrographs of the same sample. Nanosphere lithography was employed to control the dimension of the SiNPs (diameter and inter-pillar spacing). The distance between the centers of any two pillars was fixed at $650 \mathrm{~nm}$, and this value was determined by using PS nanoparticles with that particular diameter. The density of the SiNP array was measured to be $\sim 2.7 \times 10^{6}$ pillars $/ \mathrm{mm}^{2}$. Since the opening between the pillars was $\sim 200 \mathrm{~nm}$, it was considered to be sufficient for the conformal coating of the SiNP array with PEDOT:PSS, without the addition of any organic molecules (see the supporting information figure S1). The inset in the lower left corner in Figure 3(a) shows the top view of PEDOT:PSS coated SiNP array textured surface. The thickness of the PEDOT:PSS layer was approximately $40 \mathrm{~nm}$. SiNP arrays with average heights of $200 \mathrm{~nm}, 400 \mathrm{~nm}, 800 \mathrm{~nm}$, and $1200 \mathrm{~nm}$ were fabricated by etching the sample for $30 \mathrm{~s}, 60 \mathrm{~s}, 120 \mathrm{~s}$, and $180 \mathrm{~s}$, respectively. The fabricated SiNP array samples underwent a rigorous cleaning procedure as described in a previous paragraph, 
followed by an $\mathrm{HF}$ dip for native oxide removal. The samples were then immediately transferred to the ALD chamber to deposit an ultrathin $\mathrm{Al}_{2} \mathrm{O}_{3}$ interface layer. $\mathrm{Al}_{2} \mathrm{O}_{3}$ deposition was carried out at the relatively low temperature of $\sim 110^{\circ} \mathrm{C}$ to minimize native oxide growth. Longer time exposures at higher temperatures produce unacceptably thick native oxide interface layers on the samples. Figure 3(b) shows the collected TEM image where it is possible to discern the native oxide layer with a thickness of $\sim 1.28 \mathrm{~nm}$, grown during 20 cycles of $\mathrm{ALD} \mathrm{Al}_{2} \mathrm{O}_{3}$ deposition at $170^{\circ} \mathrm{C}$. Thicker interface layers impose higher barrier potentials for charge carriers to tunnel through, hindering the collection efficiency of the device. Therefore, we reduced the platen temperature and the number of cycles during ALD deposition to minimize the thickness of the native oxide layer grown at the interface. Figure 3(c) shows the TEM image of the PEDOT:PSS layer on a c-Si sample with an ultrathin (6 cycles) $\mathrm{ALD} \mathrm{Al}_{2} \mathrm{O}_{3}$ deposited at $110^{\circ} \mathrm{C}$. The presence of an ultrathin $\mathrm{Al}_{2} \mathrm{O}_{3}$ at the interface between the Si and PEDOT:PSS is also confirmed by the EDX spectra obtained at the interface (see supporting information in Figure S2). The EDX analysis was performed using an EDAX detector attached to a JEOL-ARM microscope operating at $200 \mathrm{kV}$. The deposition of a sub-nanometer $\mathrm{Al}_{2} \mathrm{O}_{3}$ also improves the wettability of PEDOT:PSS on the $\mathrm{SiNP}$ array textured surface (see Figure 3(d)). The contact angle is greatly reduced from $39.6^{\circ}$ to $7.10^{\circ}$ upon the inclusion of an ultrathin $\mathrm{Al}_{2} \mathrm{O}_{3}$ interface layer.

\subsection{Effect of SiNPs height on cell performance}

The height of the SiNPs plays an important role in device performance. The current-voltage characteristics of the SiNP/PEDOT:PSS hybrid solar cells having different nanopillar heights were measured under $100 \mathrm{~mW} / \mathrm{cm}^{2}$ illumination. Five cells were fabricated for each value of the silicon nanopillar height and their electrical performance was measured. Figure 4 depicts the average value of short circuit current density $\left(J_{S C}\right)$, open circuit voltage $\left(V_{O C}\right)$, fill factor $(F F)$ and power conversion efficiency $(P C E)$ of the fabricated devices as a function of SiNP height. The measured value of short circuit current density for the fabricated SiNP/PEDOT:PSS solar cells, increases with the increase in nanopillar height, reaching a maximum of $29.5 \mathrm{~mA} / \mathrm{cm}^{2}$ at SiNP height of $0.4 \mu \mathrm{m}$ (see Figure 4a), beyond which it decreases quasi-linearly to $21.2 \mathrm{~mA} / \mathrm{cm}^{2}$ as height is further increased to $1.2 \mu \mathrm{m}$. Similar effects have also been observed by Shiu et al. ${ }^{14}$ and He et al. ${ }^{19}$. The unique antireflection property of the SiNP array textured surface is directly reflected in the measured value of $J_{S C}$ of the SiNP/PEDOT:PSS solar cell. The maximum $J_{S C}$ of 29.5 $\mathrm{mA} / \mathrm{cm}^{2}$ for a SiNP array textured cell with SiNP height of $0.4 \mu \mathrm{m}$ is almost $36.6 \%$ greater than a planar/PEDOT:PSS cell. On the other hand, the measured open circuit voltage of the SiNP/PEDOT:PSS solar cells was observed to decrease continuously from a maximum value of $538 \mathrm{mV}$ to a minimum of $490 \mathrm{mV}$ as the SiNP height varied from $0.2 \mu \mathrm{m}$ to $1.2 \mu \mathrm{m}$ (see Figure 4a). This can be attributed to an increased junction recombination with increases in surface area. The power conversion efficiency of the SiNP/PEDOT:PSS solar cells produced, reached a maximum value of $9.65 \%$, for a nanopillar height of $0.4 \mu \mathrm{m}$, which compares favorably to the $7.02 \%$ observed for a planar/PEDOT:PSS cell. This is mainly due to the increase in short circuit current density and fill factor for the device, despite the slight decrease in $V_{O C}$. A promising fill factor value of 62 was achieved for a SiNP/PEDOT:PSS hybrid cell which also compares favorably to $F F$ of 60 for a planar/PEDOT:PSS solar cell. This could be attributed to an increased carrier separation due to the increased junction area. 
Furthermore, the SiNP/PEDOT:PSS heterojunction provides a shorter pathway for the minority charge carriers towards the respective electrode. The measured photovoltaic parameter of the proposed hybrid solar cells are summarized in Table 1. Compared to the schemes employing random SiNWs, a SiNP array has enough spacing between the pillars for conformal coating employing PEDOT:PSS without the addition of other organic molecules (See the supporting information in Figure S1). Furthermore, one of the major drawbacks of SiNW/PEDOT:PSS hybrid devices resides on the wire length, thus, the longer they are the more difficult it is for the PEDOT:PSS to coat every wire conformally, completely and uniformly to form the required core shell structure. Frequently, pin-hole regions are created that form a local shunt, which ultimately deteriorate the $V_{O C}$ and $F F$ of the device.

To further investigate the influence of SiNP height on the PV performance of the fabricated devices, the external quantum efficiency ( $E Q E)$ of the SiNP/PEDOT:PSS solar cells with different pillar heights was measured and the corresponding graphs are shown in Figure 5. The measured $E Q E$ improves with the increase in SiNP height up to $0.4 \mu \mathrm{m}$ due to light trapping effects. However, beyond $0.4 \mu \mathrm{m}$ the $E Q E$ decreases drastically with increases in SiNP height, despite of their effective light trapping (see the reflectance spectra in Figure 5), especially in the wavelength range of 400 to $800 \mathrm{~nm}$. This can be attributed to increases in carrier recombination with the increase in SiNP height. The SiNPs with taller pillar heights fabricated by the metal assisted chemical etching method produce more surface defects, resulting in shorter carrier lifetime and, therefore, a higher carrier recombination velocity. Since most of the short wavelengths photons are absorbed in a few tenths of nanometer of silicon, the most drastic drop in $E Q E$ is observed at those wavelengths for devices with a larger height, while there is no significant change for wavelengths $>800 \mathrm{~nm}$, as most of the long wavelength photons are absorbed in the bulk region of the device. This suggests that an effective surface passivation (junction passivation) is inevitable to improve the electrical performance of SiNP/PEDOT:PSS solar cells.

\subsection{Effect of $\mathrm{Al}_{2} \mathrm{O}_{3}$ passivation layer on cell performance}

One factor limiting the efficiency of SiNP/PEDOT:PSS hybrid cell is the low carrier collection efficiency due to increased surface recombination, in spite of having better light absorption characteristics. The open circuit voltage of a SiNP/PEDOT:PSS solar cells, irrespective of pillar height, is observed to be smaller compared to their planar/PEDOT:PSS counterparts. To reduce the recombination at the nanotextured silicon surface with a SiNP/ PEDOT:PSS structure we employed an ultrathin $(<1 \mathrm{~nm}) \mathrm{ALD} \mathrm{Al}_{2} \mathrm{O}_{3}$ as an interface passivation layer. $\mathrm{ALD} \mathrm{Al}_{2} \mathrm{O}_{3}$ was chosen as a passivation layer due to its unique chemical and field effect passivation characteristics, as well as the ability of ALD to deposit high quality, conformal films on high aspect ratio features, with an angstrom-level control of the film thickness at low temperatures.

Different samples were prepared, with increases in the thickness of the $\mathrm{Al}_{2} \mathrm{O}_{3}$ interface layer and its effects on photovoltaic performance was measured. The height of the SiNPs was fixed at $0.4 \mu \mathrm{m}$. Figure 6 shows the curves of current density versus voltage characteristic for SiNP/PEDOT:PSS hybrid solar cells with increases in the number of the ALD cycles 
during the deposition of the $\mathrm{Al}_{2} \mathrm{O}_{3}$ interfacial layer. The average photovoltaic performance of the SiNP/ALD- $\mathrm{Al}_{2} \mathrm{O}_{3} / \mathrm{PEDOT}$ :PSS hybrid solar cells are summarized in Table 2. It was found that the power conversion efficiency of the devices increased with increases in the thickness of the $\mathrm{Al}_{2} \mathrm{O}_{3}$ interface layer, reached its maximum value of $10.56 \%$ for six cycles ALD $\mathrm{Al}_{2} \mathrm{O}_{3}$, while the $P C E$ of the same device without $\mathrm{Al}_{2} \mathrm{O}_{3}$ was $9.65 \%$. This can be attributed mainly to the increased open circuit voltage of the device. The maximum open

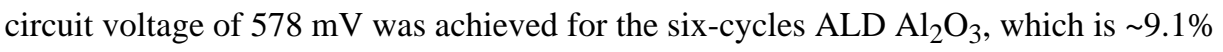
higher compared to the same device without $\mathrm{Al}_{2} \mathrm{O}_{3}$ interface layer. The maximum short circuit current density of the cell with the $\mathrm{Al}_{2} \mathrm{O}_{3}$ barrier layer was $30.1 \mathrm{~mA} / \mathrm{cm}^{2}$ compared to $29.5 \mathrm{~mA} / \mathrm{cm}^{2}$ for a cell without $\mathrm{Al}_{2} \mathrm{O}_{3}$ despite the slight decrease in $F F$. Further increases in thickness of the $\mathrm{Al}_{2} \mathrm{O}_{3}$ layer have a deleterious effect in device performance especially due to increases in the series resistance (increases in the insulation barrier for the carriers) which ultimately has an adverse effect on $V_{O C}, J_{S C}$ and $F F$ of the device. The $\mathrm{Al}_{2} \mathrm{O}_{3}$ layer in $\mathrm{SiNP} / \mathrm{Al}_{2} \mathrm{O}_{3} / \mathrm{PDEOT}$ :PSS structure also prevents the oxidation of Si. The performance of the proposed device with an ultrathin $\mathrm{ALD} \mathrm{Al}_{2} \mathrm{O}_{3}$ barrier layer was observed to remain unaltered after 72 hours of exposure to ambient, while the corresponding device without the ALD $\mathrm{Al}_{2} \mathrm{O}_{3}$ layer degraded significantly (see the supporting information in Table $\mathrm{S} 1$ ). This can be attributed to be due to a thicker native oxide film grown at the interface between $\mathrm{Si}$ and the PEDOT:PSS layer, which imposes an increased barrier height for the carriers to be collected.

The $V_{O C}$ value of the SiNP/PEDOT:PSS sample with an optimized ALD $\mathrm{Al}_{2} \mathrm{O}_{3}$ interface layer $(\sim 578 \mathrm{mV})$ compares favorably to values reported for SiNW/PEDOT:PSS hybrid solar cells ${ }^{19,21}$. High $V_{O C}$ values usually need a careful interface preparation for effective carrier collection, which is commonly not associated with defective interfaces. For the ideal diode model $(\mathrm{n}=1)$ the Shockley equation for $V_{O C}$ can be expressed as ${ }^{22}$

$$
V_{O C}=\frac{n k_{B} T}{q} \ln \left(\frac{J_{S C}}{J_{O}}+1\right)
$$

Where, $J_{O}$ is the saturation current density and $\mathrm{n}, k_{B}, T$ and $q$ are diode ideality factor, Boltzman constant, absolute temperature and elementary charge, respectively. We believe the slight increase in $J_{S C}\left(\sim 0.6 \mathrm{~mA} / \mathrm{cm}^{2}\right)$ for a SiNP/PEDOT:PSS solar cell with an optimized $\mathrm{Al}_{2} \mathrm{O}_{3}$ barrier layer does not sufficiently warrant the relatively large increase in $V_{O C}(\sim 57 \mathrm{mV})$ observed. Assuming a similar $J_{O}$ for both SiNP/PEDOT:PSS solar cells with and without $\mathrm{Al}_{2} \mathrm{O}_{3}$ barrier layer, the increase in $J_{S C}$ would lead to a $V_{O C}$ gain defined by the equation

$$
\Delta V_{O C}=\frac{k_{B} T}{q} \ln \left(\frac{J_{S C} w / A L D}{J_{S C} w o / A L D}\right)
$$

Using this relation, we anticipated a $V_{O C}$ gain of $\sim 1 \mathrm{mV}$, which is smaller than the experimentally measured voltage gain. Ostensibly, the assumption of a constant $J_{O}$ is not warranted. To further investigate the underlying reasons for the observed voltage gain, we measured and graphed the dark current density versus voltage characteristics of the hybrid SiNP/PEDOT:PSS solar cells with and without $\mathrm{Al}_{2} \mathrm{O}_{3}$ interface layer. The observations 
indicate that the dark current density is suppressed significantly after employing the ultrathin $\mathrm{Al}_{2} \mathrm{O}_{3}$ barrier layer (see Figure 7). From the best fitting of the dark $J$ - $V$ characteristic curves at the forward bias condition, we extracted the values of saturation current density $\left(J_{O}\right)$ and diode ideality factor $(\mathrm{n})$, which is defined by the relation,

$$
\ln (J)=\ln \left(J_{0}\right)+\left(\frac{q}{n k_{B} T}\right) V
$$

We obtained the value of $J_{O}$ to be $0.48 \mu \mathrm{A} / \mathrm{cm}^{2}$ for a SiNP/PEDOT:PSS hybrid cell with an $\mathrm{Al}_{2} \mathrm{O}_{3}$ barrier layer, which was lower than that of a cell without a barrier layer, namely, 2.19 $\mu \mathrm{A} / \mathrm{cm}^{2}$. The ideality factors of 2.06 and 2.21 , respectively, were obtained for the SiNP/ PEDOT:PSS cells with and without the $\mathrm{Al}_{2} \mathrm{O}_{3}$ barrier layer. Using $J s c=30.1 \mathrm{~mA} / \mathrm{cm}^{2}, J_{O}=$ $0.48 \mu \mathrm{A} / \mathrm{cm}^{2}$ and $\mathrm{n}=2.06$, for the fabricated SiNP/PEDOT:PSS solar cells with $\mathrm{Al}_{2} \mathrm{O}_{3}$ barrier layer, and employing those values in equation (1), we obtain a $V_{O C}$ of $592 \mathrm{mV}$, which falls within $2.4 \%$ of the experimentally observed value of $578 \mathrm{mV}$. The reduction in the dark current is thought to provide evidence for a reduced carrier recombination with improved junction quality. However, the fill factor of the device is relatively low compared to other pure inorganic photovoltaic devices. We calculated the ideal $F F$ of the SiNP/ PEDOT:PSS hybrid solar cells in the absence of series and shunt resistances using the equation defined by ${ }^{38}$

$$
F F=\frac{v_{O C}-\ln \left(v_{O C}+0.72\right)}{v_{O C}+1}
$$

Where $v o c=V_{O C} /\left(n k_{B} T / q\right)$ is the normalized open circuit voltage. Using $V_{O C}=578 \mathrm{mV}$ and $\mathrm{n}=2.06$, we obtain the ideal $F F$ of $\sim 71 \%$ for the proposed hybrid device compared to the measured $F F$ of $60 \%$. This suggests that there is a significant electrical loss due to the parasitic series and shunt resistances of the device. The electrical loss can be suppressed by forming an ohmic contact on both the front and the rear sides of the device. This could be accomplished by forming a back surface field on the rear side of the device and creating a metal grid electrode on the front.

Hence, we believe that there is still room to improve the electrical performance of the proposed hybrid device.

\section{Conclusions}

A promising hybrid solar cell device based on highly ordered silicon nanopillar (SiNP) arrays and poly (3,4-ethylene-dioxythiophene):polystyrenesulfonate (PEDOT:PSS) has been described. Relatively simple, low temperature processing methods were employed for the fabrication of the proposed solar cell. The effect of SiNP height on the solar cell performance of the device was investigated. The $P C E$ of a SiNP/PEDOT:PSS hybrid cell with an optimized SiNP height of $0.4 \mu \mathrm{m}$ was observed to be $9.65 \%$. With the utilization of an ultrathin $\mathrm{ALD}$ deposited $\mathrm{Al}_{2} \mathrm{O}_{3}$ junction passivation layer, we observed a short circuit current density and an open circuit voltage as high as $30.1 \mathrm{~mA} / \mathrm{cm}^{2}$ and $578 \mathrm{mV}$ respectively, which led to a $P C E$ value in excess of $10.56 \%$. An ideal fill factor of $\sim 71 \%$ was calculated for the hybrid device described herein which is significantly higher than the 
measured value of $\sim 60 \%$. Thus, there is a noticeable electrical loss in the proposed device. Further investigation is needed to fully explore the proposed hybrid SiNP/PEDOT:PSS hybrid solar cell.

\section{Supplementary Material}

Refer to Web version on PubMed Central for supplementary material.

\section{Acknowledgments}

We thank Dr. Mike Gerhold, Technical Manager of the U.S. Army Research Office, for the financial support provided for this project (ARO grant number W911NF-13-1-0110). This project was also supported by a grant from the National Institute on Minority Health and Health Disparities (G12MD007591) from the National Institutes of Health. The authors would also like to acknowledge for the Ferro Corporation, CA, USA for technical support.

\section{References}

1. Aberle AG, Altermatt PP, Heiser G, Robinson SJ, Wang A, Zhao J, Krumbein U, Green MA. J Appl Phys. 1995; 77(7):3491-3504.

2. Zhao J, Wang A, Green MA, Ferrazza F. Appl Phys Lett. 1998; 73:1991-1993.

3. Garnett E, Yang P. Nano Lett. 2010; 10:1082-1087. [PubMed: 20108969]

4. Oh J, Yuan HC, Branz HM. Nat Technol. 2012; 7:743-748.

5. Hoth CN, Schilinsky P, Choulis SA, Brabec CJ. Nano Lett. 2008; 8:2806-2813. [PubMed: 18683989]

6. Zhao G, He Y, Li Y. Adv Mater. 2010; 22:4355-4358. [PubMed: 20589774]

7. He F, Yu L. J Phys Chem Lett. 2011; 2:3102-3113.

8. Kim JY, Lee K, Coates NE, Moses D, Nguyen TQ, Dante M, Heeger AJ. Science. 2007; 317:222225. [PubMed: 17626879]

9. Mei J, Ogawa K, Kim YG, Heston NC, Arenas DJ, Nasrollahi Z, McCarley TD, Tanner DB, Reynolds JR, Schanze KS. ACS Appl Mater Interfaces. 2009; 1:150-161. [PubMed: 20355767]

10. Seo JH, Gutacker A, Sun Y, Wu H, Huang F, Cao Y, Scherf U, Heeger AJ, Bazan GC. J Am Chem Soc. 2011; 133:8416-8419. [PubMed: 21557557]

11. Liu CY, Holman ZC, Kortshagen UR. Adv Func Mater. 2010; 20:2157-2158.

12. Liu CY, Holman ZC, Kortshagen UR. Nano Lett. 2009; 9:449-452. [PubMed: 19113966]

13. He L, Jiang C, Rusli, Lai D, Wang H. Appl Phys Lett. 2011; 99:021104(1)-021104(3).

14. Shiu SC, Chao JJ, Hung SC, Yeh CL, Lin CF. Chem Mater. 2010; 22:3108-3113.

15. Huynh WU. Science. 2002; 295:2425-2427. [PubMed: 11923531]

16. Avasthi S, Lee S, Loo YL, Sturm JC. Adv Mater. 2011; 23:5762-5766. [PubMed: 22109841]

17. Wright M, Uddin A. Sol Energy Mater Sol Cells. 2012; 107:87-111.

18. Wu F, Cui Q, Qiu Z, Liu C, Zhang H, Shen W, Wang M. ACS Appl Mater Interfaces. 2013; 5:3246-3254. [PubMed: 23570319]

19. He L, Jiang C, Wang H, Lai D, Rusli. ACS Appl Mater Interfaces. 2012; 4:1704-1708. [PubMed: 22391479]

20. Lu W, Wang C, Yue W, Chen L. Nanoscale 2011. 3:3631-3634.

21. Jeong S, Garnett EC, Wang S, Yu Z, Fan S, Brongersma ML, McGehee MD, Cui Y. Nano Lett. 2012; 12:2971-2976. [PubMed: 22545674]

22. Pietsch M, Bashouti MY, Christiansen S. J Phys Chem C. 2013; 117:9049-9055.

23. Zhu Y, Song T, Zhang F, Lee ST, Sun B. Appl Phys Lett. 2013; 102:113504(1)-113504(4).

24. Lu W, Chen Q, Wang B, Chen L. Appl Phys Lett. 2012; 100:023112(1)-023112(4).

25. Bashouti, MY.; Pietsch, M.; Brönstrup, G.; Sivakov, V.; Ristein, J.; Christiansen, S. Prog Photovolt: Res Appl. 2013. http://dx.doi.org/10.1002/pip.2315 
26. Khatri I, Tang Z, Liu Q, Ishikawa R, Ueno K, Shirai H. Appl Phys Lett. 2013; 102:063508(1)063508(5).

27. Moiz SA, Nahhas AM, Um HD, Jee SW, Cho HK, Kim SW, Lee JH. Nanotechnol. 2012; 23:145401(1)-145401(7).

28. Han SE, Chen G. Nano Lett. 2010; 10:1012-1015. [PubMed: 20141156]

29. Yang TC, Huang TY, Lee HC, Lin TJ, Yen TJJ. Electrochem Soc. 2012; 159:B104-B108.

30. Pudasaini PR, Ayon AA. Opt Comm. 2012; 285:4211-4214.

31. Christesen JD, Zhang X, Pinion CW, Celano TA, Flynn CJ, Cahoon JF. Nano Lett. 2012; 12:60246029. [PubMed: 23066872]

32. Pudasaini PR, Elam D, Ayon AA. J Phys D: Appl Phys. 2013; 46:235104(1)-235104(8).

33. Zhang F, Sun B, Song T, Zhu X, Lee S. Chem Mater. 2011; 23:2084-2090.

34. He L, Jiang C, Wang H, Lai D, Rusli. Appl Phys Lett. 2012; 100:073503(1)-073503(3).

35. Cheung CL, Nikolic RJ, Reinhardt CE, Wang TF. Nanotechnol. 2006; 17:1339-1343.

36. Mikhael B, Elise B, Xavier M, Sebastian S, Johann M, Laetitia P. ACS Appl Mater Interfaces. 2011; 3:3866-3873. [PubMed: 21882843]

37. Pudasaini PR, Ayon AA. Microelecrtron Eng. 2013; 110:126-131.

38. Green MA. Sol Cells. 1982; 7:337-340. 


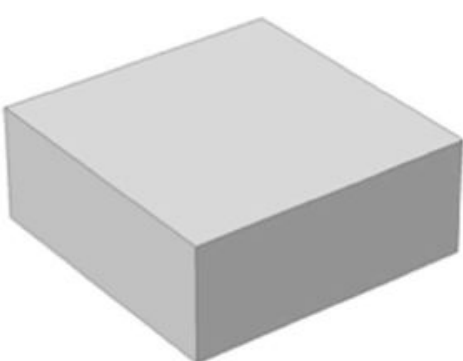

(a)

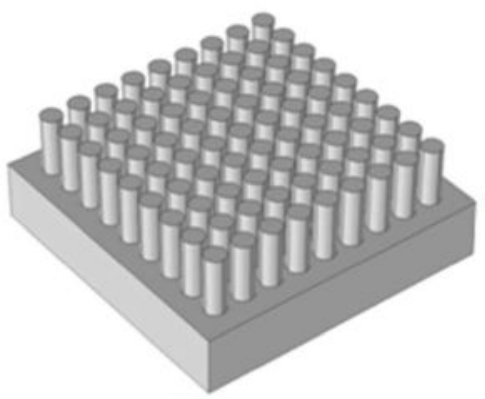

(f)

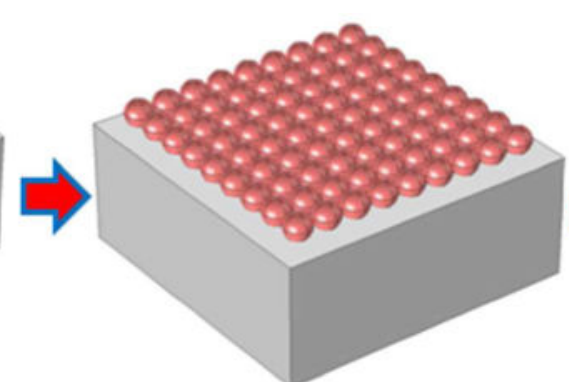

(b)

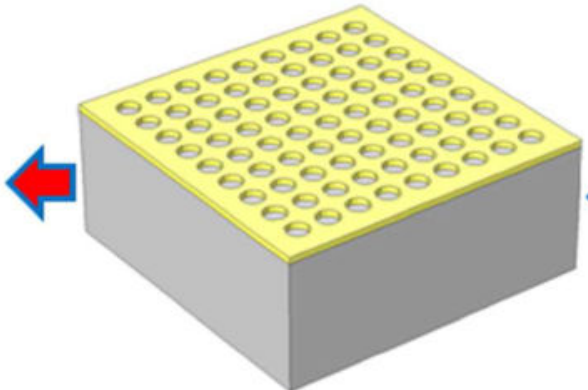

(e)

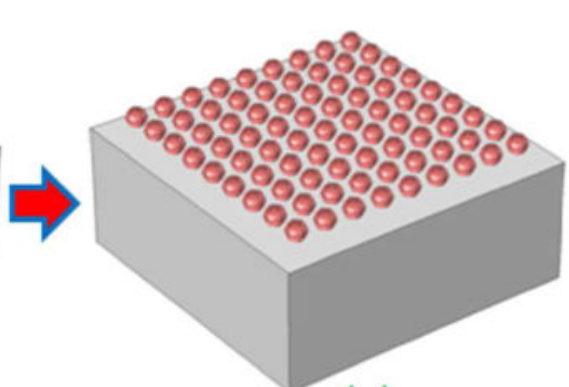

(c)

Figure 1.

Schematic illustration of the fabrication process of a periodic SiNP array. (a) RCA clean of the n-type Si (100) wafer, (b) self assembled monolayer of PS nanoparticles on the Si surface, (c) etch back of PS nanoparticles by using an $\mathrm{O}_{2}$ plasma barrel etcher, (d) etchedback PS nanoparticles covered by a few nanometers of $\mathrm{Au}$, (e) honeycomb like Au pattern on Si created by removing PS nanoparticles, (f) periodic SiNP array fabricated by metal assisted chemical etching process. 


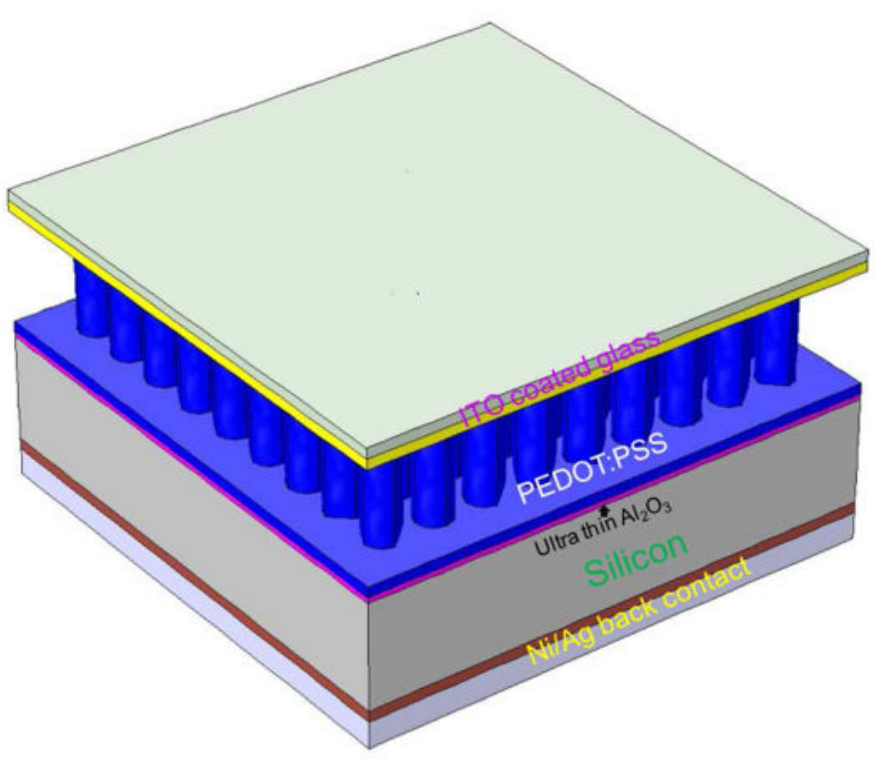

(a)

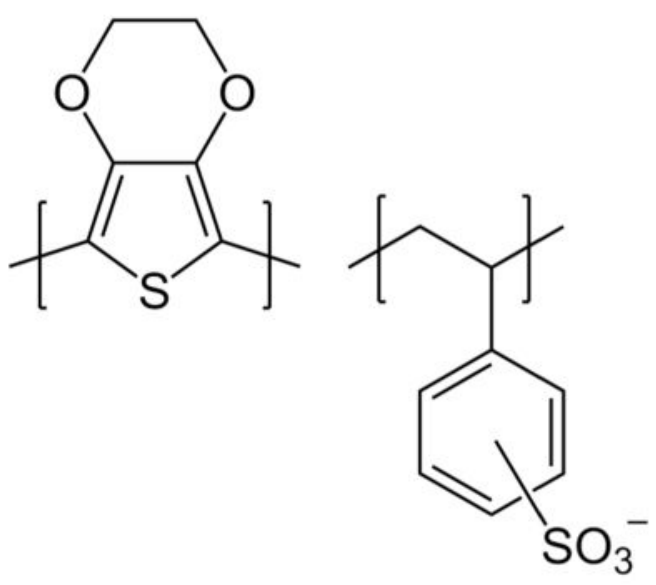

(b)

Figure 2.

(a) Schematic illustration of the fabricated SiNP/PEDOT:PSS solar cell. (b) chemical structure of PEDOT:PSS. 

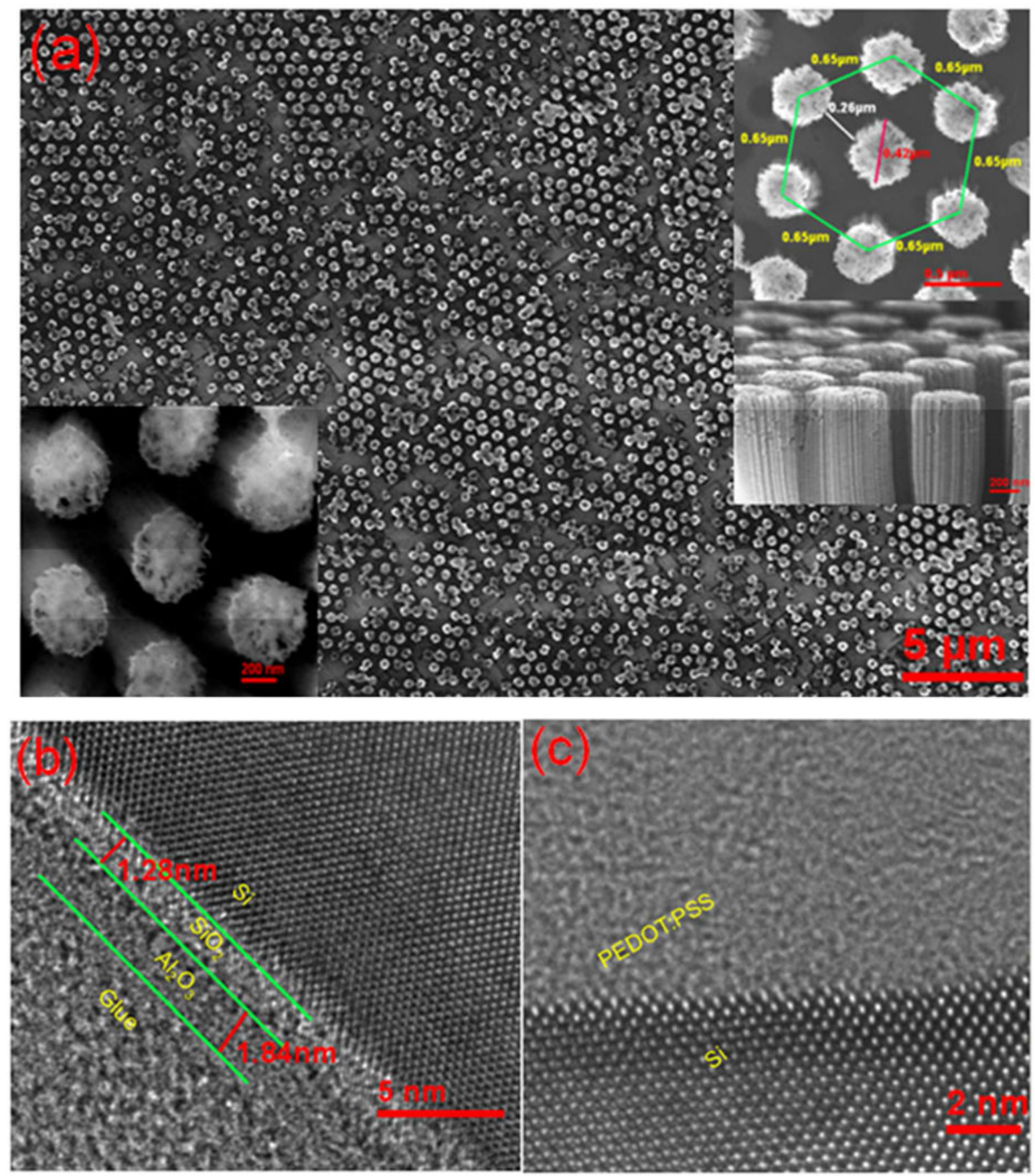

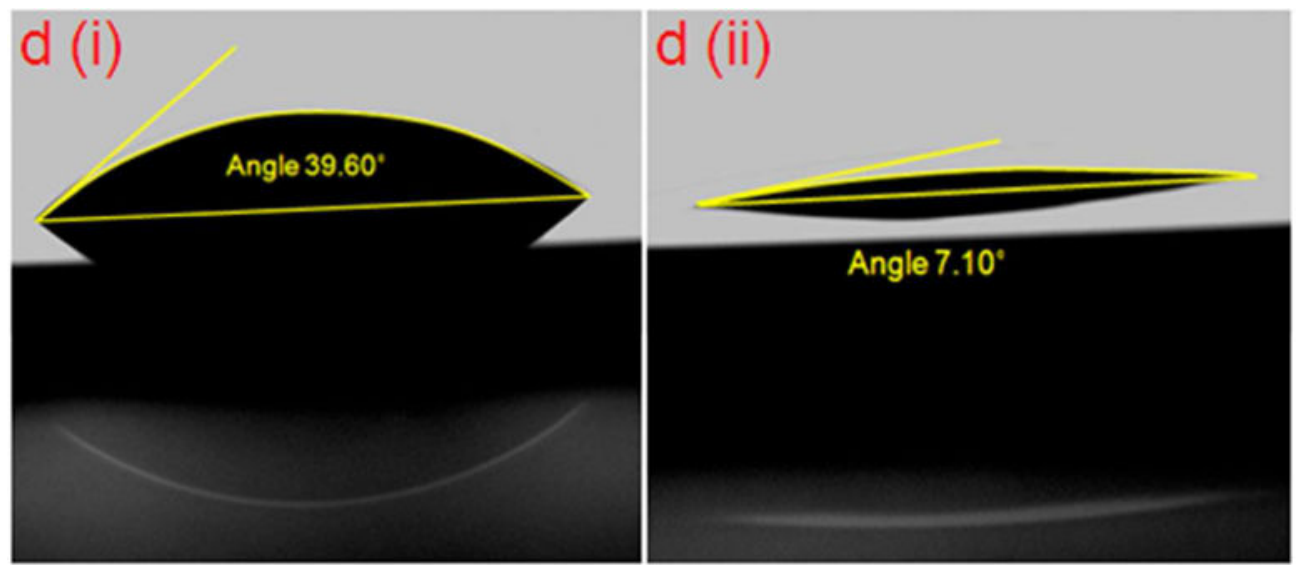

Figure 3.

SEM micrographs of (a) top view of a SiNP array textured silicon surface; the inset on the upper right corner includes higher magnification images of the same sample, where it is possible to discern the hexagonal order of the SiNP array. The inset on the lower left corner shows a high magnification image of the SiNP array, coated with the transparent and conductive polymer PEDOT:PSS by spin casting at $2000 \mathrm{rpm}$. (b) High Resolution TEM micrograph of a 20 -cycle $\mathrm{ALD} \mathrm{Al}_{2} \mathrm{O}_{3}$ deposited on silicon at $170^{\circ} \mathrm{C}$, showing a $1.28 \mathrm{~nm}$ native oxide layer grown during the deposition process, (c) TEM image of the PEDOT:PSS on $\mathrm{Si}$ interface, with a 6-cycle $\mathrm{ALD} \mathrm{Al}_{2} \mathrm{O}_{3}$ layer deposited at $110^{\circ} \mathrm{C}$ without a discernible native oxide layer grown at the interface. (d) Photograph of an IPA-diluted PEDOT:PSS on (i) a hydrogen-terminated SiNP array textured surface (ii) and SiNP array textured surface coated with an ultrathin $\mathrm{ALD} \mathrm{Al}_{2} \mathrm{O}_{3}$ layer, contrasting the different surface wettability. 

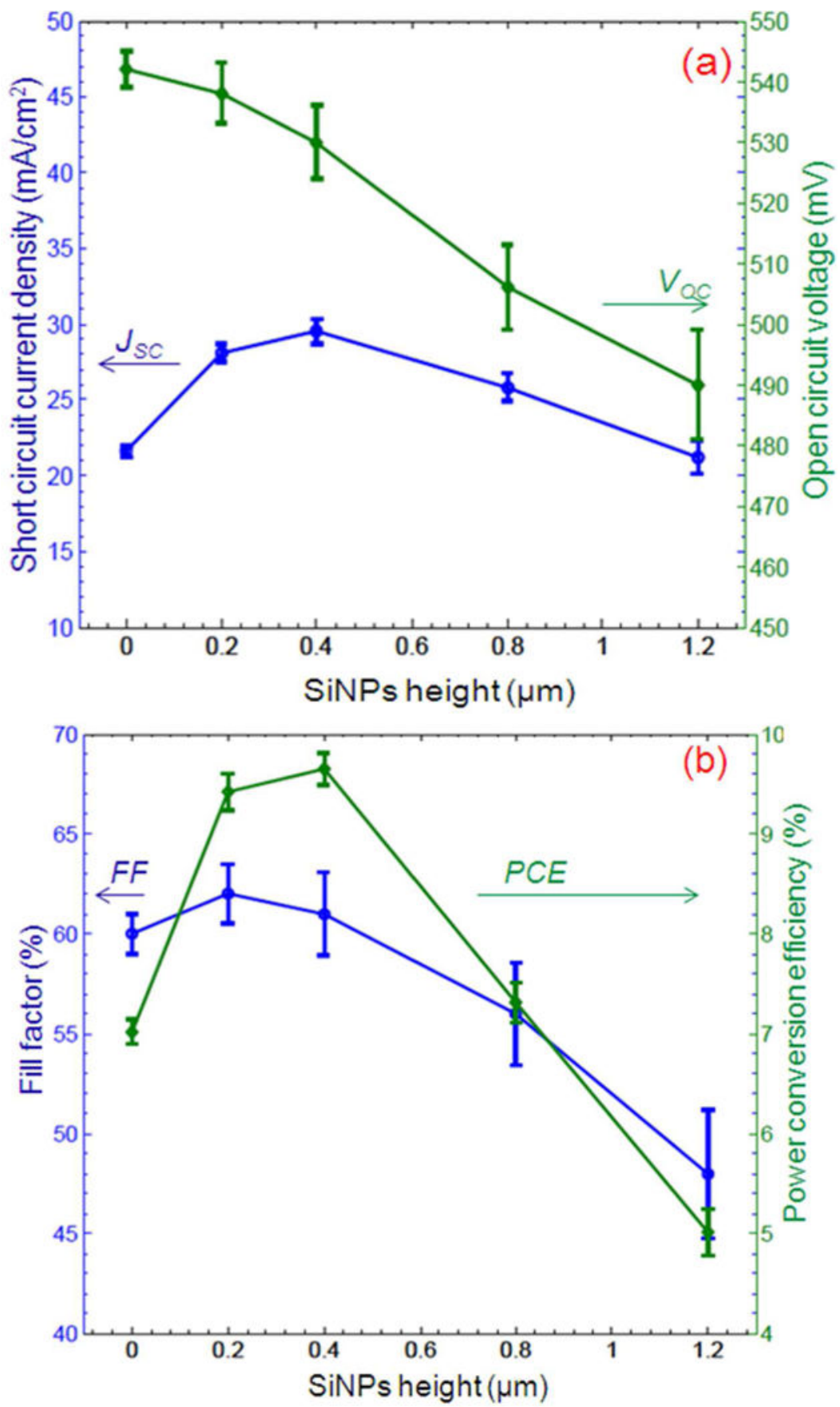

Figure 4.

Average photovoltaic performance parameters of (a) $J_{S C}$ and $V_{O C}$ and (b) $F F$ and $P C E$ of the SiNP/PEDOT:PSS solar cell as a function of SiNP height. 


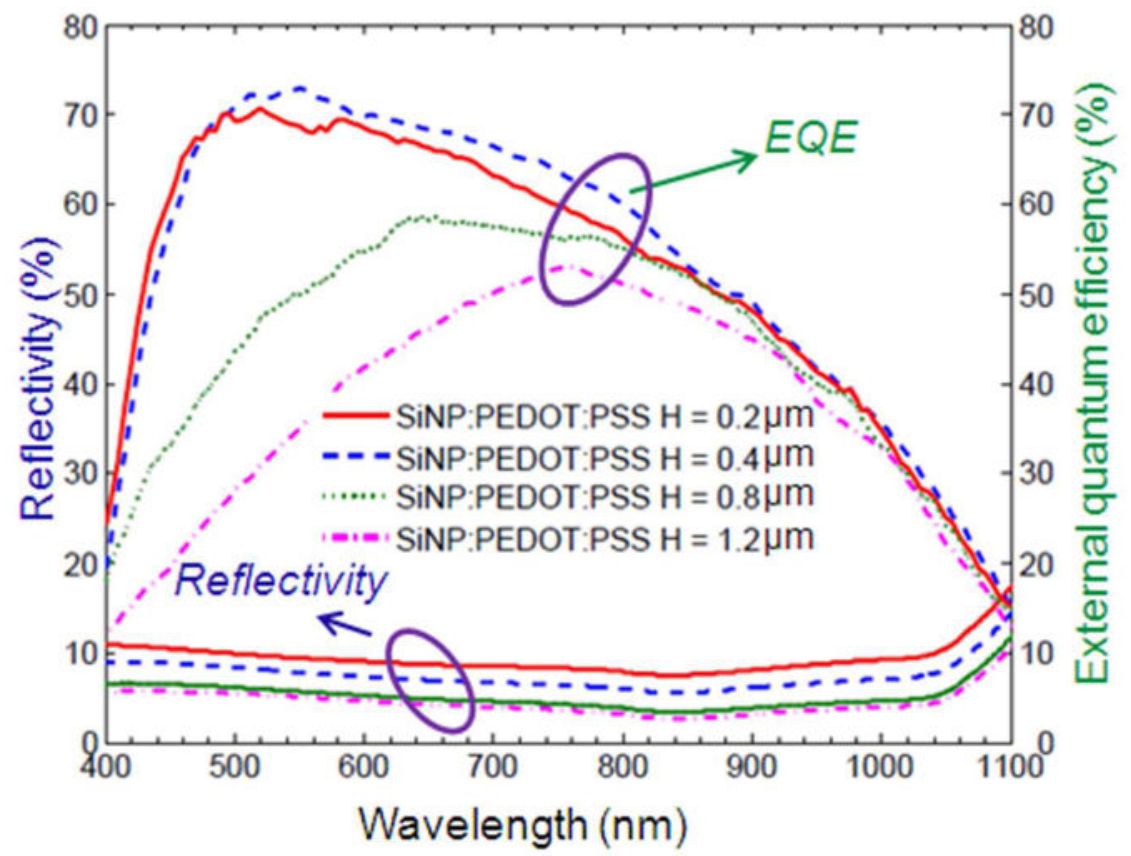

Figure 5.

Reflectivity spectra (\%) and measured external quantum efficiency (\%) of the SiNP/ PEDOT:PSS hybrid solar cells with different SiNP height. 


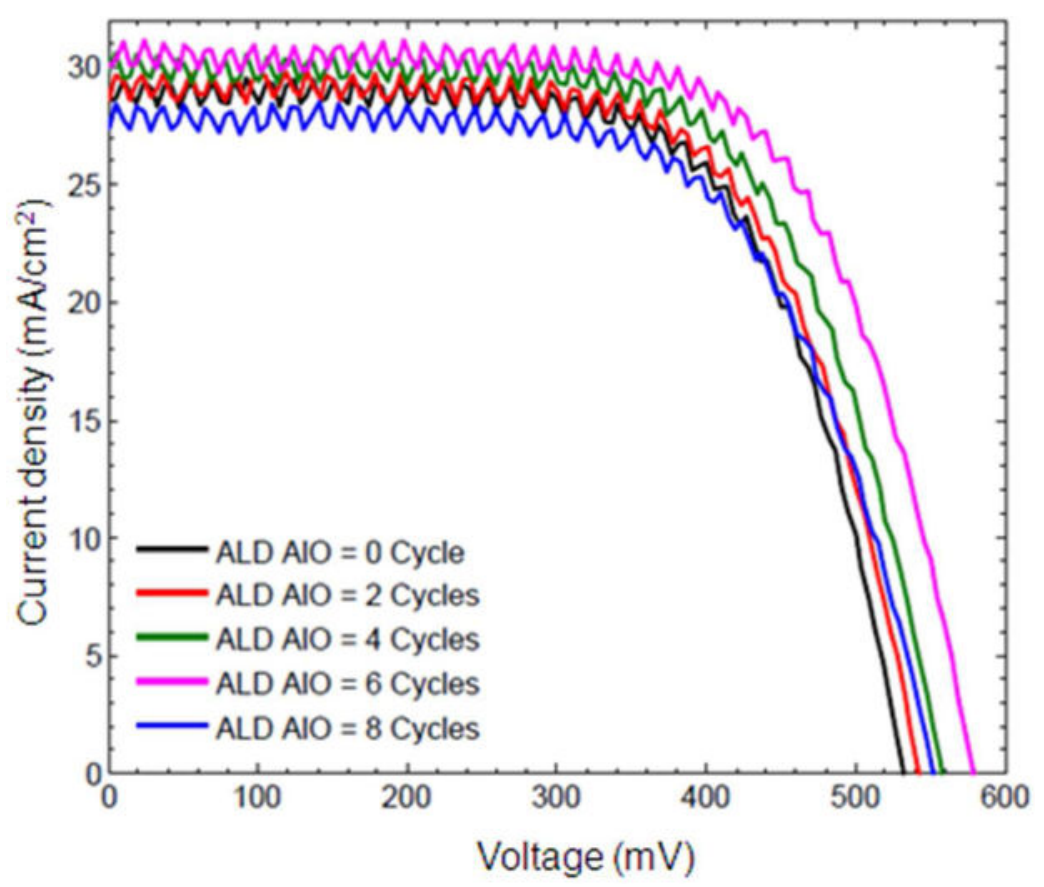

Figure 6.

Current density versus voltage characteristic curves for SiNP/PEDOT:PSS hybrid solar cells with increases in the number of cycles during the deposition of the $\mathrm{ALD} \mathrm{Al}_{2} \mathrm{O}_{3}$ interfacial layer. The height of the SiNPs was fixed at $0.4 \mu \mathrm{m}$. 


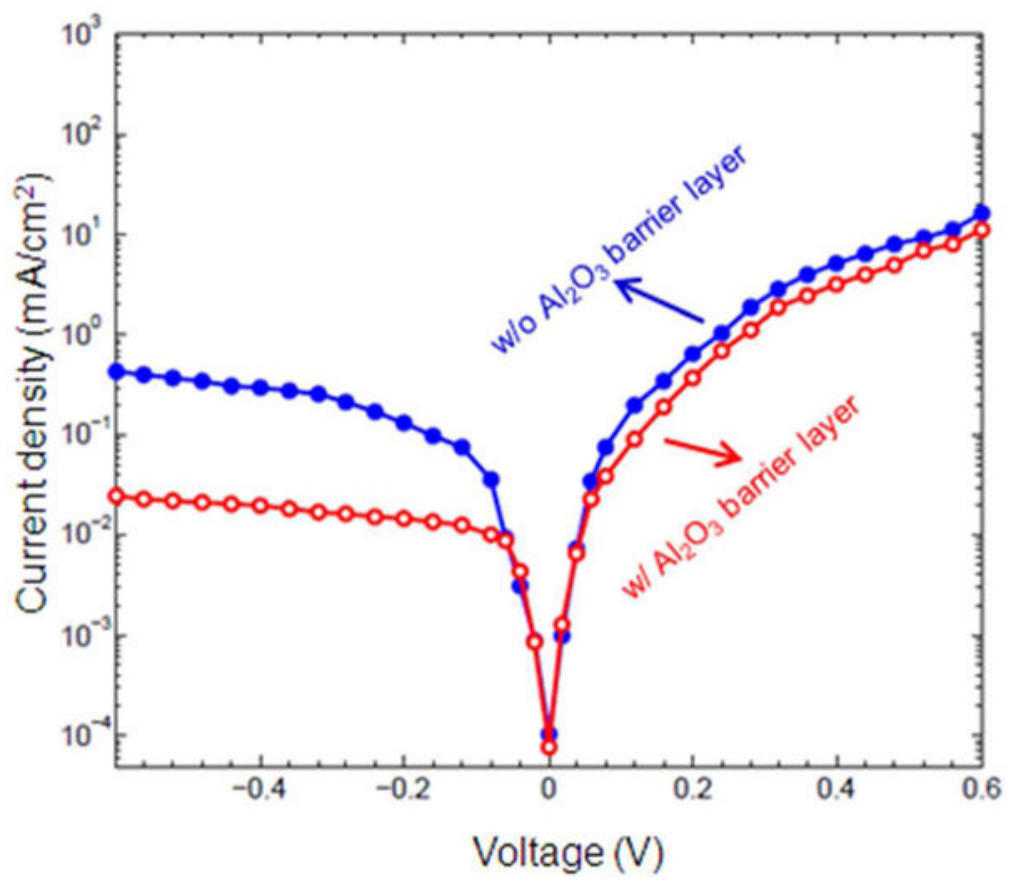

Figure 7.

Dark $J$ - $V$ characteristic curves for SiNP/PEDOT:PSS hybrid solar cells with and without (open circles) an $\mathrm{Al}_{2} \mathrm{O}_{3}$ interface layer. The height of the SiNPs was fixed at $0.4 \mu \mathrm{m}$. 
Table 1

Average photovoltaic properties of the hybrid SiNP/PEDOT:PSS solar cells with different SiNP height.

\begin{tabular}{lcccc}
\hline Cell types & $\boldsymbol{V}_{\boldsymbol{O C}}(\boldsymbol{m} \boldsymbol{V})$ & $\boldsymbol{J}_{\boldsymbol{S C}}\left(\boldsymbol{m A} / \boldsymbol{c m}^{2}\right)$ & $\boldsymbol{F F}(\boldsymbol{\%})$ & $\boldsymbol{P C E}(\boldsymbol{\%})^{\boldsymbol{a}}$ \\
\hline Planar/PEDOT:PSS & 542 & 21.6 & 60.1 & $7.02 \pm 0.12$ \\
$0.2 \mu \mathrm{m}$ SiNP/PEDOT:PSS & 538 & 28.1 & 62.0 & $9.42 \pm 0.18$ \\
$0.4 \mu \mathrm{m}$ SiNP/PEDOT:PSS & 530 & 29.5 & 61.2 & $9.65 \pm 0.16$ \\
$0.8 \mu \mathrm{m}$ SiNP/PEDOT:PSS & 506 & 25.8 & 56.2 & $7.31 \pm 0.20$ \\
$1.2 \mu \mathrm{m}$ SiNP/PEDOT:PSS & 490 & 21.2 & 48.0 & $5.01 \pm 0.23$ \\
\hline
\end{tabular}

${ }^{a}$ The statistics present the error range of five measured samples with $95 \%$ confidence interval. 


\section{Table 2}

Influence of $\mathrm{ALD} \mathrm{Al}_{2} \mathrm{O}_{3}$ interface layer thickness on the photovoltaic performance of the SiNP/PEDOT:PSS solar cells.

\begin{tabular}{lcccc}
\hline Cell types & $\boldsymbol{V}_{\boldsymbol{O C}}(\boldsymbol{m} \boldsymbol{V})$ & $\boldsymbol{J}_{\boldsymbol{S C}}\left(\boldsymbol{m A} / \boldsymbol{c m}^{2}\right)$ & $\boldsymbol{F F}(\boldsymbol{\%})$ & $\boldsymbol{P C E}(\boldsymbol{\%})$ \\
\hline SiNP/0C-ALD/PEDOT:PSS & 530 & 29.5 & 61.2 & $9.65 \pm 0.16$ \\
SiNP/2C-ALD/PEDOT:PSS & 546 & 29.2 & 60.9 & $9.72 \pm 0.14$ \\
SiNP/4C-ALD/PEDOT:PSS & 557 & 29.8 & 59.2 & $9.79 \pm 0.15$ \\
SiNP/6C-ALD/PEDOT:PSS & 578 & 30.1 & 59.8 & $10.56 \pm 0.14$ \\
SiNP/8C-ALD/PEDOT:PSS & 552 & 28.2 & 58.3 & $9.02 \pm 0.17$ \\
SiNP/10C-ALD/PEDOT:PSS & 524 & 26.4 & 54.6 & $7.51 \pm 0.23$ \\
\hline
\end{tabular}

${ }^{a}$ The statistics present the error range of five measured samples with $95 \%$ confidence interval. 